\title{
Hydrogen Bonding in Copoly(ether-urea)s and Its Relationship with the Physical Properties
}

\author{
A. Marcos-Fernández,* A. E. Lozano, L. González, and A. Rodríguez \\ Instituto de Ciencia y Tecnología de Polímeros (CSIC), Calle J uan de la Cierva 3, \\ E 28006 Madrid, Spain
}

Received December 27, 1996; Revised Manuscript Received March 6, $1997^{\otimes}$

\begin{abstract}
The evolution of hydrogen bonding with temperature in three copoly(ether-urea)s with no phase separation has been studied by Fourier transform infrared spectroscopy (FT-IR) in the region of the carbonyl absorption of the urea groups. Assignment of the bands was made by supposing the existence of chains of urea groups linked by bifurcated hydrogen bonds. Quantum mechanical calculations of these chains fitted qualitatively with the experimental results. Dynamic mechanical and calorimetric experiments showed that the apparition of the band related to the "internal" urea groups of the chains produces a decrease in the glass transition of the polyether moiety of the copolymer and that prior to it a transition that we related to the glass transition of the bis(ureaphenyl)methane units takes place.
\end{abstract}

\section{Introduction}

The copoly(ether-urea)s are a subclass of polymers that constitute the latest generation of reaction injection molding (RIM) systems and bel ong to a wider family of polymers with the generic name of polyurethanes. These polymers are, in general, built up by the reaction of a long chain oligomer, a polyisocyanate, and a short chain monomer called a chain extender. While for a true polyurethane the long chain oligomer and the chain extender end groups that react with the isocyanate group are hydroxyls, for the copoly(ether-urea)s the long chain ol igomer is an amine-functionalized polyether and the chain extender is a polyamine (usually aromatic), which results in the formation of urea groups when reacted with the isocyanate groups. The reaction of the chain extender with the isocyanate forms the chemical species defined as the hard segments (HS), which at ambient temperature act as cross-links. The long chain oligomer forms the chemical species defined as soft segments (SS). The thermodynamic incompatibility between soft and hard segments produces a microphase-separated structure with domains rich in a particular segment that dominates the physical properties of these block copolymers. Therefore, one of the most important aspects in the study of these copolymers is the characterization of this phaseseparated structure, the main goal being to find the structure-physical properties relationships.

Since Cooper ${ }^{1}$ postulated the existence of this phaseseparated structure, several techniques have being used to characterize it. Some techniques (electron microscopy, small angle X-ray scattering (SAXS)) are useful for the characterization of the morphology of the structure, and others (differential scanning calorimetry (DSC), dynamic mechanical thermal analysis (DMTA), infrared (IR) spectroscopy, and also SAXS) have been used to evaluate qualitatively and in some cases quantitatively the mixing of segments in the domains and in the interface between domains. ${ }^{2}$

In the infrared spectra of these polymers, two regions can be used to characterize the urethane or/and urea groups present: the region at approximately 3500-3000 $\mathrm{cm}^{-1}$ related to the $\mathrm{N}-\mathrm{H}$ stretching vibration and the region at approximately $1750-1600 \mathrm{~cm}^{-1}$ related to the

\footnotetext{
${ }^{\otimes}$ Abstract published in Advance ACS Abstracts, May 15, 1997.
}

carbonyl $(\mathrm{C}=\mathrm{O})$ stretching vibration. The $\mathrm{N}-\mathrm{H}$ stretching region has been shown to be inadequate to characterize the hydrogen bonding of the urethane/urea groups, especially when the long chain oligomer is a polyether. In this case, it has been demonstrated that, when hydrogen bonding occurs to an ether group, the $\mathrm{N}-\mathrm{H}$ vibration absorbs at nearly the same frequency as that when a bridge to a carbonyl group is formed. ${ }^{3}$

The carbonyl region, on the other hand, has been widely used to characterize, at least semiquantitatively, the hydrogen-bonding state of these polymers and to correlate this to the phase separation in the system. This has been done by identifying and separating the contribution, to the total absorption, of the nonassociated and associated $\mathrm{C}=\mathrm{O}$ groups and making use of two assumptions: the absorption coefficient remains nearly invariable with the degree of hydrogen bonding, and the $\mathrm{C}=\mathrm{O}$ groups involved in hydrogen bonding are present in the hard segment domains.

The work presented in this paper deals with the hydrogen bonding in copoly(ether-urea)s and its effect on the physical properties, revising the band assignment on the carbonyl region in these polymers. For the first time, to our knowledge, quantum mechanical calculations have been used in the study of hydrogen bonding in these polymers.

\section{Results and Discussion}

IR Studies. As al ready stated, interpretation of the $\mathrm{N}-\mathrm{H}$ region is difficult, so we will focus on the $\mathrm{C}=\mathrm{O}$ region. The samples 600MDI, 970MDI, and 2260MDI (see Experimental Section) showed, at ambient temperature, two distinct peaks (Figure 1); a well-defined peak at $1694 \mathrm{~cm}^{-1}$ and a broad peak in the vicinity of 1666 $\mathrm{cm}^{-1}$. When heated, these peaks shift to higher frequencies and a sudden drop in intensity takes place when the temperature is increased from approximately $170{ }^{\circ} \mathrm{C}$ to approximately $180^{\circ} \mathrm{C}$. This drop in intensity is related to the decrease in thickness of the vertically mounted sample. When the temperature is increased from $180^{\circ} \mathrm{C}$ to $200^{\circ} \mathrm{C}$, these two peaks become less welldefined, merging into a very broad peak at $200^{\circ} \mathrm{C}$. F or the copolymer 970MDI, a new peak centered around $1644 \mathrm{~cm}^{-1}$ appears at $190{ }^{\circ} \mathrm{C}$ at the same time that a shoulder does at $3317 \mathrm{~cm}^{-1}$ in the $\mathrm{N}-\mathrm{H}$ region, both increasing at $200{ }^{\circ} \mathrm{C}$. On cooling, these peaks appear 


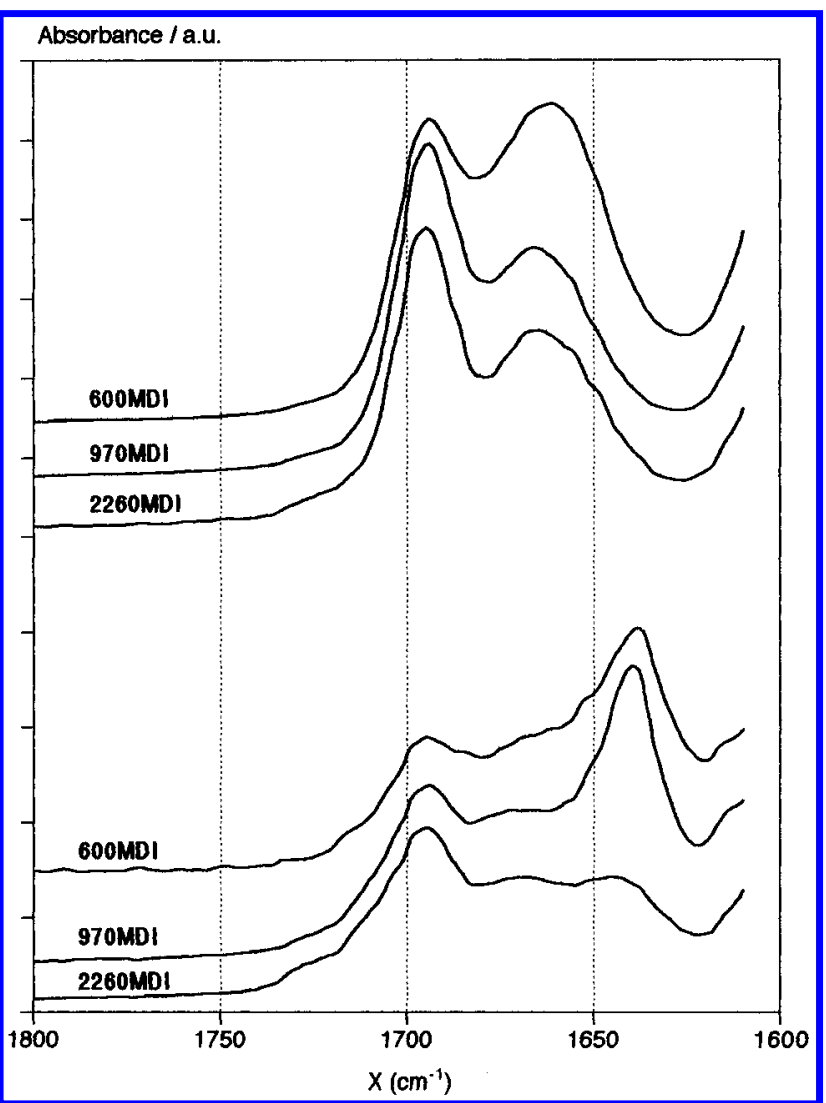

Figure 1. I nfrared spectra of the copolymers in the carbonyl region taken at ambient temperature for the untreated samples (top) and for the samples heated to $200^{\circ} \mathrm{C}$ (bottom). a.u. $=$ arbitrary units.

clearly in the copolymers 600MDI and 2260MDI, shifting to slightly lower frequencies when the temperature decreases. In Figure 2 the changes with temperature in the $\mathrm{C}=\mathrm{O}$ region for copol ymer $970 \mathrm{MDI}$ are displayed, and in Figure 1 the final spectra for the copolymers heated to $200{ }^{\circ} \mathrm{C}$ are shown.

Before we discuss the details of the carbonyl peaks, it will be useful to review the assignments of the absorption peaks in previous studies on (poly)urethanes, (poly)urethane-ureas, and (poly)ureas.

Once the phase-separated morphology present in polyurethanes (with chain extender and therefore with hard segments) was postulated, the $\mathrm{C}=\mathrm{O}$ absorption region was fitted to two components, one related to the free urethane and the other to the hydrogen-bonded urethane groups. ${ }^{4,5}$ The free urethane groups were assumed to be present in the soft segment domains and the hydrogen-bonded groups in the hard segment domains, so that the ratio of both peaks could be used as an index of phase separation. Studies on models gave a similar value for the absorption coefficient of the carbonyl group, irrespective of the hydrogen bonds on the group, giving way to the use of the area of these two peaks for the purpose of quantifying the phase separation. ${ }^{6-9}$

The first infrared studies on poly(urethane-urea)s split the carbonyl absorption of the urea group into two components, in a way completely similar to that for polyurethanes, ${ }^{10}$ the main difference in the hydrogen bonding being the capability of the carbonyl moiety of the urea group to interact simultaneously with two $\mathrm{N}-\mathrm{H}$, forming hydrogen bonds in different directions, ${ }^{11}$ which would explain the superior mechanical properties and thermal resistance of these polymers compared to

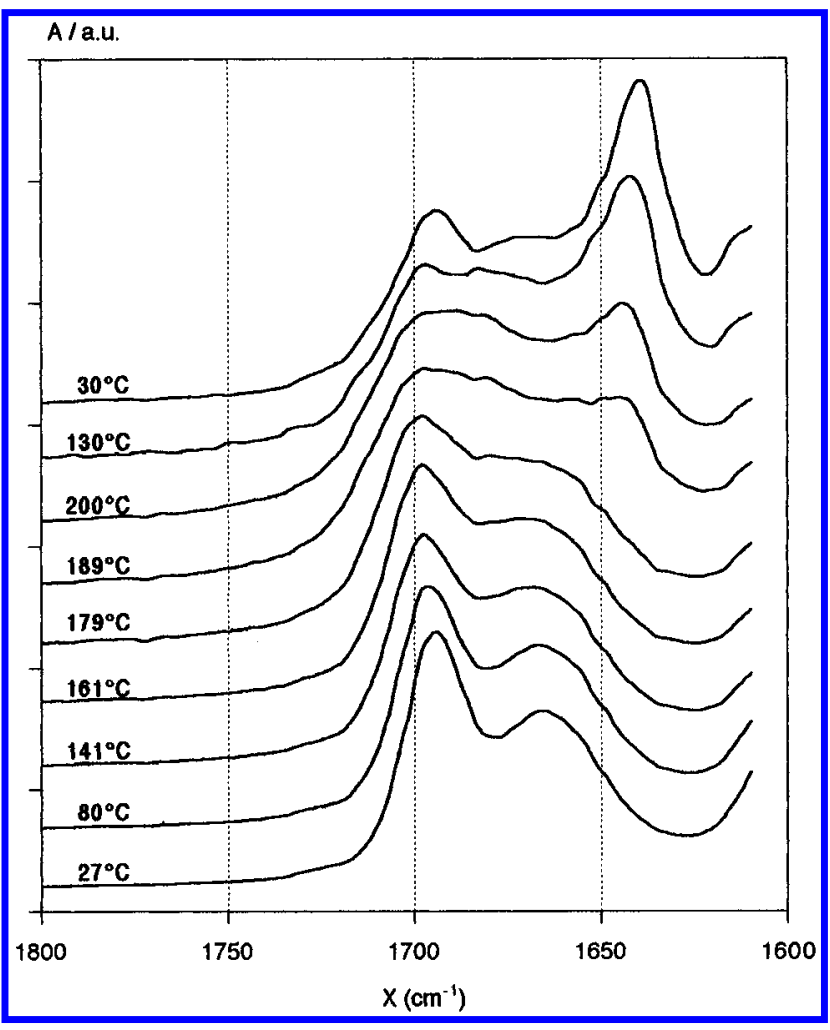

Figure 2. Changes on the carbonyl absorption for copolymer 970MDI on heating and cooling (from bottom to top).

polyurethanes, capable of forming a single hydrogen bond. The peak in the vicinity of $1700 \mathrm{~cm}^{-1}$ was related to nonassociated $\mathrm{C}=\mathrm{O}$ and the peak around $1640 \mathrm{~cm}^{-1}$ to hydrogen-bonded $\mathrm{C}=\mathrm{O}$. When an additional peak ${ }^{12}$ was found in some occasions between these two at approximately $1660 \mathrm{~cm}^{-1}$, a "loosely ordered" or "disordered" hydrogen-bonded urea group was invoked, leaving the peak at $1640 \mathrm{~cm}^{-1}$ as belonging to "ordered" hydrogen-bonded urea groups. The work of Born and Hespe in 1985 on model ureas ${ }^{13}$ demonstrated that the urea groups could form bifurcated hydrogen bonds with each carbonyl oxygen bonded to both the $\mathrm{N}-\mathrm{H}$ dipoles of the opposite urea group, rather than in different directions. ${ }^{11}$ This gave meaning to the term "ordered" hydrogen-bonded urea groups, and the peak at lower frequencies was then attributed to bifurcated hydrogen bonds. ${ }^{14-18}$ Another peak has been found in ureas formed by reaction of isocyanate with water, a reaction commonly used in the manufacture of foams, leaving the peaks of the $\mathrm{C}=\mathrm{O}$ absorption region in ureas as currently assigned to, from higher to lower frequencies: "soluble" urea, "free" urea, "intermediate"/"disordered"|"I oosely ordered" urea and "ordered"/"bifurcated" urea. The last two peaks are the urea-urea hydrogenbonded species, which, we should remember, are considered to be only in the hard segment domains.

Returning to urethanes, Coleman and co-workers, ${ }^{3}$ studied blends of polyether with a model amorphous urethane hard segment (toluene diisocyanate and butanediol) and they concluded that the urethane groups associated, forming chains of intermolecular hydrogen bonds, as al ready depicted by Bonart for crystalline hard segments. ${ }^{11}$ The main statement made by them was that the "free" component of the $\mathrm{C}=\mathrm{O}$ band could be viewed not as isolated urethane groups in the polyether phase, but as the "end" groups of the chains of hydrogenbonded urethane groups. No mention is made whether these chains are exclusive of the hard segments. In this 
study it is also noticeable, when the $\mathrm{C}=\mathrm{O}$ absorption is fitted with two peaks, that the width of the hydrogenbonded $\mathrm{C}=\mathrm{O}$ peak is explained by the variability of the strength in the hydrogen bonds. When in certain systems a third peak was noticed, 19,20 two peaks were then explicitly assigned to hydrogen bonding, one of them being "disordered" and the other "ordered", as al ready done for the urea groups.

Recently, an advance on the explanation of the origin of the absorption peaks in the $\mathrm{C}=\mathrm{O}$ region in urethanes was discussed. ${ }^{21-23}$ In copolyurethanes synthesized without chain extender, and therefore without phase separation or hard domains, the possibility of the existence of five absorption peaks was postulated. The origin of these peaks was said to be in the chains of intermolecular hydrogen bonds, being assigned, from higher to lower frequencies, to (1) $\mathrm{C}=\mathrm{O}$ from a urethane group with $\mathrm{C}=\mathrm{O}$ and $\mathrm{N}-\mathrm{H}$ nonassociated; (2) $\mathrm{C}=\mathrm{O}$ from a urethane group with the $\mathrm{C}=\mathrm{O}$ free and $\mathrm{N}-\mathrm{H}$ associated either to an ether or to a $\mathrm{C}=\mathrm{O}$ dipole; (3) $\mathrm{C}=\mathrm{O}$ from a urethane group with the $\mathrm{C}=\mathrm{O}$ hydrogen-bonded and $\mathrm{N}-\mathrm{H}$ free ("head" urethane), and $\mathrm{C}=\mathrm{O}$ from a urethane group forming a dimer with another urethane group; (4) $\mathrm{C}=\mathrm{O}$ from a urethane group with the $\mathrm{C}=\mathrm{O}$ hydrogenbonded and the $\mathrm{N}-\mathrm{H}$ associated to an ether ("head" urethane); (5) $\mathrm{C}=\mathrm{O}$ from a urethane group with both the $\mathrm{C}=\mathrm{O}$ and the $\mathrm{N}-\mathrm{H}$ hydrogen-bonded to other urethane groups ("inside" urethane). Type 2 corre sponds to the "free" urethane of Coleman, and types 3-5 would correspond to the wide hydrogen-bonded peak of Coleman. It is worthy to remark that the polyurethane in this study is free from chain extender, which means that these chains could in principle be found in the soft segment domains of a copolyurethane with a phaseseparated structure.

These principles have been used for the assignment of the peaks in the $\mathrm{C}=\mathrm{O}$ region on our copoly(etherurea)s. Wide angle X-ray diffraction (WAXD) graphs showed that copolymers 600MDI and 970MDI were amorphous and the crystalline peaks found in copolymer 2260MDI were identified as crystalline ethylene oxide (EO) units and disappeared on melting at $37-38{ }^{\circ} \mathrm{C}$ (maximum on DSC), leaving an amorphous halo. No maximum was found, nor appreciable scattering on the detector, in SAXS for these copolymers (above the melting point of EO crystals for 2260MDI), which demonstrated that no phase separation was present and only one phase existed in these systems. In Figure 3 the WAXD and SAXS diffractograms for copolymer 970MDI are displayed.

The infrared peaks were identified as foll ows (Figure 4) on the basis of the supposition of the existence of chains of bifurcated hydrogen bonds of different lengths and by anticipating some results from quantum mechanical calculations:

(1) $1694 \mathrm{~cm}^{-1}: \mathrm{C}=\mathrm{O}$ from a urea group with the $\mathrm{C}=\mathrm{O}$ nonassociated and the $\mathrm{N}-\mathrm{H}$ associated to the $\mathrm{C}=\mathrm{O}$ of the other urea group, or "top" end of the chain.

(2) $1660-1670 \mathrm{~cm}^{-1}: \mathrm{C}=\mathrm{O}$ from a urea group with the $\mathrm{C}=\mathrm{O}$ hydrogen-bonded and the $\mathrm{N}-\mathrm{H}$ bonded to an ether group, or "bottom" end group of the chain, as the main contribution, and al so some contribution from the "internal" ureas for long (from four associated groups) chains.

(3) $1640 \mathrm{~cm}^{-1}: \mathrm{C}=\mathrm{O}$ from a urea group with the $\mathrm{C}=\mathrm{O}$ hydrogen-bonded and the $\mathrm{N}-\mathrm{H}$ associated to the $\mathrm{C}=\mathrm{O}$ of the other urea group, or "internal" group of the chain.
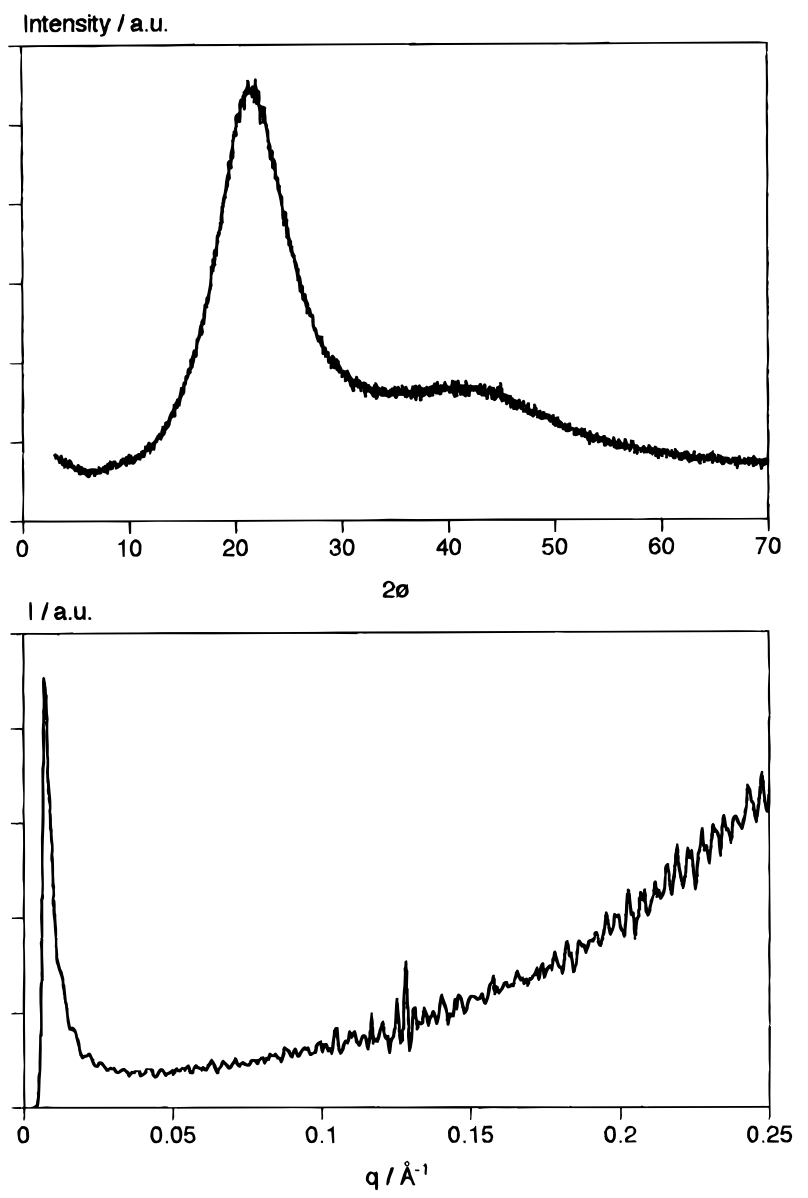

Figure 3. WAXD (top) and SAXS (bottom) diffractograms for copolymer 970MDI.

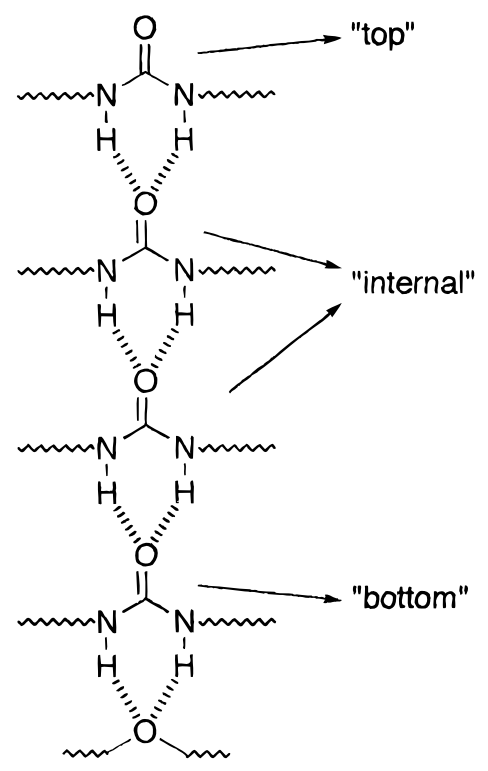

Figure 4. Representation of the chains scheme with indication of the terminology for the urea groups used in the text.

(4) A shoulder at wave numbers higher than 1695 $\mathrm{cm}^{-1}$ that becomes more evident after heating could be due to $\mathrm{C}=\mathrm{O}$ from a urea group with the $\mathrm{C}=\mathrm{O}$ nonassociated and the $\mathrm{N}-\mathrm{H}$ associated to an ether group or "isolated" urea groups. At these wave numbers it also appears that the absorption for diphenylureas is probably responsible for the small increase in this peak after heating. These diphenylurea units would arise from trans-urea reactions. ${ }^{24}$ 


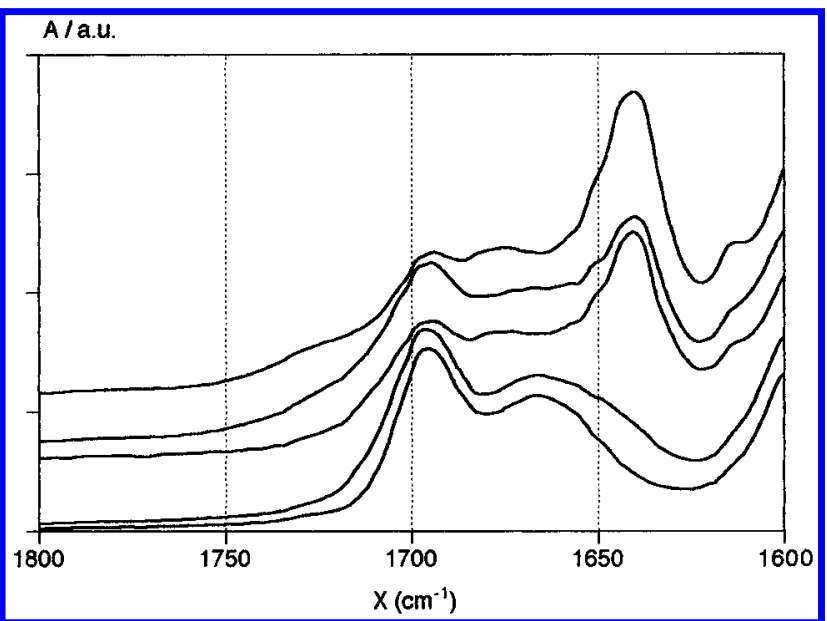

Figure 5. Infrared spectra of copolymer 970MDI in the carbonyl region taken at $65^{\circ} \mathrm{C}$ after the following treatments (from bottom to top): untreated; heated to $179{ }^{\circ} \mathrm{C}$; heated to $200{ }^{\circ} \mathrm{C}$; heated to $205^{\circ} \mathrm{C}$ in the rheometer; previous sample heated to $210^{\circ} \mathrm{C}$.

In the assignation of the peaks we have not considered the possibility of $\mathrm{N}-\mathrm{H}$ free because if this dipole was not associated with a $\mathrm{C}=\mathrm{O}$ group, then it would associate with ether groups when they are present in the system, ${ }^{3}$ which we consider is the case in our copoly(ether-urea)s.

A close view at the shape of the $\mathrm{C}=\mathrm{O}$ absorption shows that while the peaks at 1694 and $1640 \mathrm{~cm}^{-1}$ are well-defined, the peak at $1666 \mathrm{~cm}^{-1}$ is very wide, filling the gap between the other two. This observation can help us to regard the former peaks as related to welldefined species, and the latter as a peak of more complex structure.

In Figure 5 we can see the changes in $\mathrm{C}=\mathrm{O}$ for the copolymer 970MDI after different heat treatments. When heated, the hydrogen-bonding state present at ambient temperature remains invariable if the temperature of the transition at $170-180^{\circ} \mathrm{C}$ is not exceeded. When this temperature is surpassed, the peak at 1640 $\mathrm{cm}^{-1}$ appears irreversibly; the bis(ureaphenyl)methane units reach enough mobility and they start to associate. At this stage some decomposition starts to take place, as evidenced by a small peak appearing at $2340 \mathrm{~cm}^{-1}$ associated with the isocyanate group, and although it could influence the physical properties through the formation of biuret, this peak remains very small and we do not think that biuret formation is responsible for the changes in the physical properties found in these copol ymers. However, this band at $2340 \mathrm{~cm}^{-1}$ indicates that trans-urea reactions can take place and - $\mathrm{Ar}-$ $\mathrm{NHCONH}-\mathrm{Ar}$ - groups can be produced, increasing the high-frequency shoulder of the $1695 \mathrm{~cm}^{-1}$ peak. For the sample taken from the rheometer (heated with forced air), where this shoulder is more noticeable, a further contributi on to this shoul der comes from some oxidation of the sample. $3,7,25$

X-ray spectra (SAXS and WAXD) of the sample $970 \mathrm{MDI}$, after thermal annealing at $200^{\circ} \mathrm{C}$ for $15 \mathrm{~min}$, were identical to the spectra of the as-prepared sample. DSC measurements after the thermal annealing did not show any melting endotherm up to the start of thermal degradation $\left(260^{\circ} \mathrm{C}\right)$. Therefore, neither phase separation nor crystallinity is produced with the thermal annealing, and consequently, these factors cannot be related to the changes in hydrogen bonding.

Analysis of the $\mathrm{C}=\mathrm{O}$ region by decomposition in Gaussians gave only acceptable results when no less

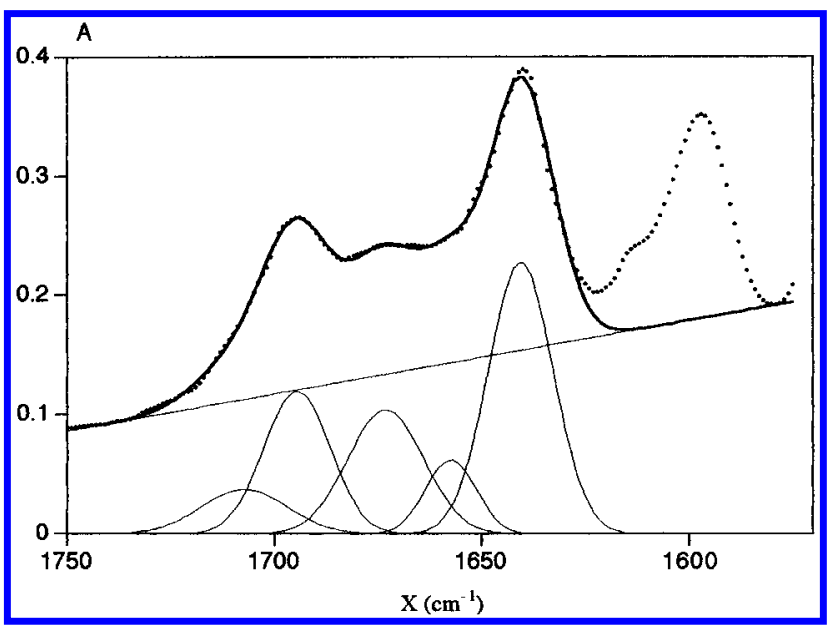

Figure 6. Example of curve fitting for the spectrum of copolymer $970 \mathrm{MDI}$ at $39{ }^{\circ} \mathrm{C}$ after thermal treatment at 200 ${ }^{\circ} \mathrm{C}$.

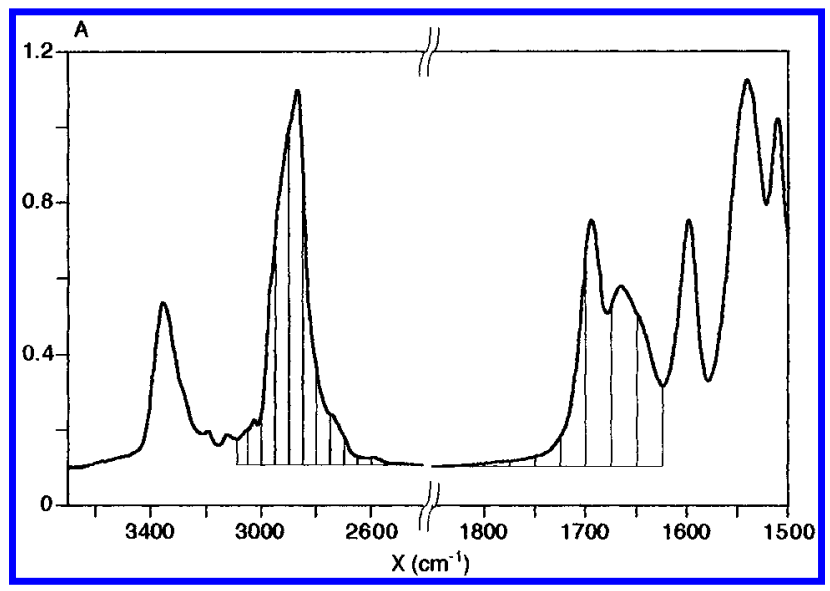

Figure 7. Baseline taken for calculating the area in the saturated $\mathrm{CH}$ region (left) and the carbonyl region (right).

than five peaks were adjusted, as shown in Figure 6. In this example, the baseline was fixed as in the figure and the only restriction imposed in the calculation was that the Gaussians assigned to "top" and "bottom" urea groups should have the same area. The resulting Gaussians had maxima at 1707, 1695, 1673, 1657, and $1641 \mathrm{~cm}^{-1}$. Attempts were made to accurately quantify, but cumulated errors arising from the baseline election, the mathematical decomposition, etc. did not lead to good results.

Some qualitative conclusions, however, can be derived from the study of copolymer 970MDI with temperature:

The area of the $\mathrm{C}=\mathrm{O}$ region, after ratioing with the saturated $\mathrm{C}-\mathrm{H}$ area (Figure 7) to minimize variations in thickness, varies in the range $4-8 \%$ ( $10 \%$ when the baseline for $\mathrm{C}=\mathrm{O}$ is as in Figure 6) with respect to the temperature changes, showing that the absorption coefficient for $\mathrm{C}=\mathrm{O}$ in the urea groups is rather independent of the state of hydrogen bonding, coincident with the results given in the literature for polyurethanes. $6,7,22$

The changes in the hydrogen-bonding state take place after the transition that produces the fall in viscosity and not simultaneously. In Figure 5 the spectrum after heating at $179^{\circ} \mathrm{C}$ (end of the transition) for $15 \mathrm{~min}$ still does not show the peak at $1640 \mathrm{~cm}^{-1}$, wher eas this peak is evident after heating at $189{ }^{\circ} \mathrm{C}$. If we represent (Figure 8) the area of saturated $\mathrm{C}-\mathrm{H}$, which represents the amount of sample, and the ratio $A\left(1640 \mathrm{~cm}^{-1}\right) /$ $A\left(2970 \mathrm{~cm}^{-1}\right)$, which is indicative of the "internal" $C=0$, 


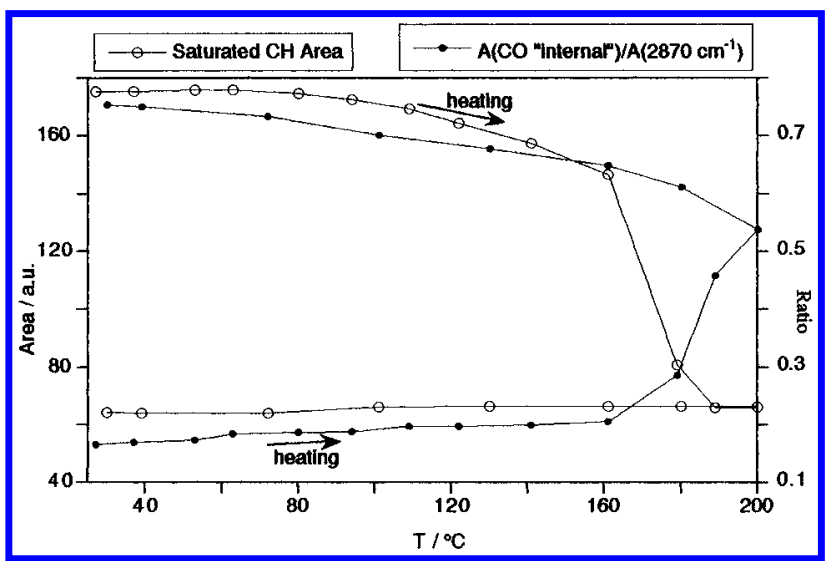

Figure 8. Changes with temperature in the saturated $\mathrm{C}-\mathrm{H}$ area and in the ratio of "internal " $\mathrm{C}=\mathrm{O}$ to absorbance at 2870 $\mathrm{cm}^{-1}$ for copolymer 970MDI.

we can observe that when the sample viscosity changes (sample thinning), the "internal" $\mathrm{C}=\mathrm{O}$ increase is small, higher temperatures are needed to obtain a fast increase. This will be confirmed later with the help of other techniques.

Quantum Mechanical Calculations. The model chosen for the calculations was dimethylurea because it is the simplest disubstituted urea and therefore has the minimum number of atoms to adjust with the computer. First, the minimum energy of a single molecule was computed, and the result was used to model a pair of molecules. The procedure was scaled up to a string of five molecules (Figure 9). For completeness, the interactions of dimethylurea with dimethyl sulfoxide and dimethyl ether were also cal culated.

Two semiempirical quantum mechanical methods were used, AM 1 and PM3. Although none of the NDDO methods (MNDO, AM1, and PM3) can predict accurately the geometry of the hydrogen bond in comparison with a flexible ab-initio basis set such as 6-31G**, the difference in energy between the correct (ab-initio) geometry and the AM 1 or PM 3 geometry is quite small. As an example, the water dimer hydrogen bonding was reproduced with an energy of $5.5 \mathrm{kcal} / \mathrm{mol}$ by $A M 1$, in accordance with the experimental value. ${ }^{26}$

Results using the PM3 method showed severe scattering, since the method is very sensitive to the arrangement of the molecules; for that reason, only results with AM1 that did not show this problem will be commented on. For the sake of clarity, in what follows we will use the nomenclature already used in the peak assignment when referring to the urea groups in a string: we will call the "top" group the group at the extreme of the string that has the $\mathrm{C}=\mathrm{O}$ nonassociated, the "bottom" group will be the group at the extreme of the string that has the $\mathrm{N}-\mathrm{H}$ nonassociated, and the "internal" group will be the group with $\mathrm{C}=\mathrm{O}$ and $\mathrm{N}-\mathrm{H}$ associated.

Regarding the bond distances, we find that although the hydrogen bond is in the range $2.15-2.21 \AA$, that is, on the order of distances found in real crystalline ureas, ${ }^{13} \mathrm{C}=\mathrm{O}$ distances are slightly overestimated (1.254-1.264 $\AA$ compared to $1.238 \AA$ taken from the previous reference) and, as a consequence, the IR frequencies calculated from them. This has already been found in semiempirical calculations on simple molecules bearing carbonyl groups; 27 thus only qualitative conclusions can be drawn from these calculations.

The calculated $\mathrm{N}-\mathrm{H}$ absorption of a molecule is composed of symmetrical and antisymmetrical vibra-

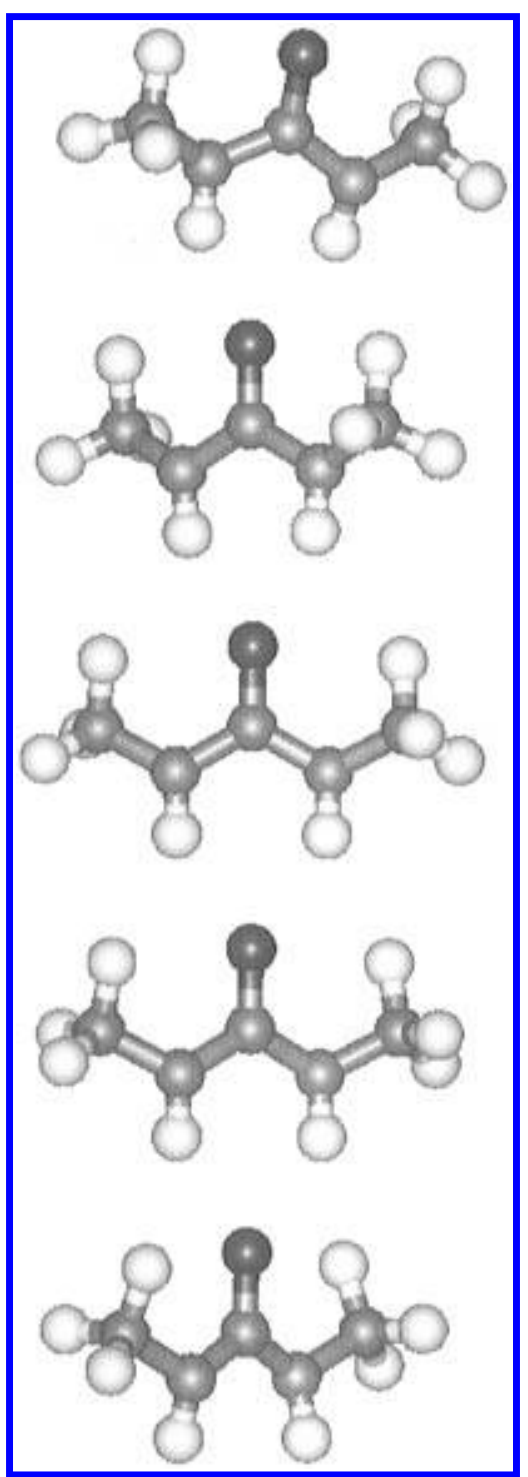

Figure 9. Graphical display of the result of the quantum mechanical calculations for a string with five dimethylurea molecules.

tions of the $\mathrm{N}-\mathrm{H}$ of the molecule. Results show that absorption for free $\mathrm{N}-\mathrm{H}$ takes place in a narrow zone, 3465-3467 cm ${ }^{-1}$ for the "isolated" molecule and 3469$3473 \mathrm{~cm}^{-1}$ for "bottom" urea groups. The $\mathrm{N}-\mathrm{H}$ hydrogenbonded to $\mathrm{C}=\mathrm{O}, \mathrm{S}=\mathrm{O}$, or ether absorbs in a wide area, $3420-3450 \mathrm{~cm}^{-1}$, separated from the free $\mathrm{N}-\mathrm{H}$. This is in a qualitative agreement with the experimental results found in the literature. $10,28,29$

The $\mathrm{C}=\mathrm{O}$ bond distance increases when hydrogen bonds are formed and the corresponding absorption decreases in frequency, as expected, but other very interesting results arise from a closer examination. In the graph number of urea molecules-wave number (Figure 10) we can observe that the "isolated" molecule absorbs at the highest frequency. The next absorption in decreasing frequency is the absorption for the $\mathrm{C}=\mathrm{O}$ nonassociated of the "top" urea groups. This absorption is rather insensitive to the length of the chain, and hence a quite defined peak should be found, in agreement with experiment. In the hydrogen-bonded $\mathrm{C}=\mathrm{O}$, the coupling of vibrations becomes stronger when the length of the chain increases with a special incidence on the "internal" groups. The $\mathrm{C}=\mathrm{O}$ absorption from "bottom" urea groups is found to be encl osed in a narrow strip, while the stronger absorption of the "internal" 


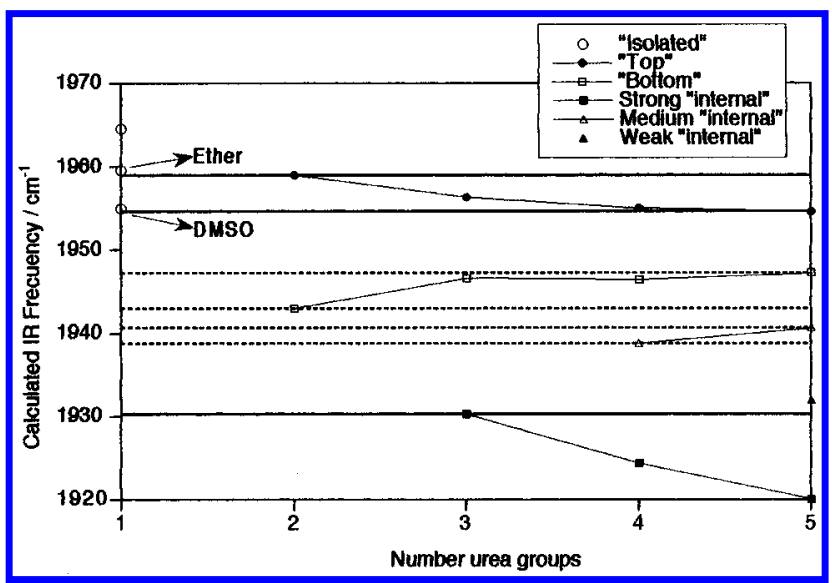

Figure 10. Calculated IR frequencies for chains of dimethylurea molecules of different lengths, showing the intervals for each type of urea group. Also included are the frequencies for "isolated" ureas hydrogen-bonded to a DMSO molecule and to an ether group.

groups is found at the lowest frequency. When the calculations include five molecules in the chain, this absorption has not reached an asymptotic behavior, and for a system with mixed chain lengths, this band is predicted to be wide in contrast with the experimental well-defined peak. The following absorption intensity of the "internal" urea groups is very close to the "bottom" $\mathrm{C}=\mathrm{O}$ absorption and, for larger chains, could merge into a single broad peak, the $1665 \mathrm{~cm}^{-1}$ experimental peak found in our copoly(ether-urea)s. For the five unit chain an absorption of negligible intensity is situated between the absorptions of strong and medium intensity. Also, the hydrogen bonding between urea groups and ether ones was modeled. Thus, when a molecule is bonded to a ether group, the $\mathrm{C}=\mathrm{O}$ absorption shifts to lower frequencies, as can be seen in Figure 10. In the chain scheme, only the "isolated" and the "bottom" $\mathrm{C}=\mathrm{O}$ would be sensitive, the "isolated" molecules appearing as a shoulder in the high-frequency side of the "top" $\mathrm{C}=\mathrm{O}$ and the "bottom" $\mathrm{C}=\mathrm{O}$ merging with the medium intensity absorption of the "internal" $\mathrm{C}=\mathrm{O}$. When an "isolated" urea mol ecule is bonded to a DMSO molecule (Figure 10), absorption occurs at the frequency of the "top" $\mathrm{C}=\mathrm{O}$. This result agrees completely with the experimental results found in the literature ${ }^{10,13,28}$ where disubstituted ureas in DMSO solution absorb at $1695 \mathrm{~cm}^{-1}$. In a recent publication, ${ }^{16}$ the band around $1665 \mathrm{~cm}^{-1}$ was assigned to $\mathrm{C}=\mathrm{O}$ from urea groups hydrogen-bonded to a single $\mathrm{N}-\mathrm{H}$. We tried to calculate the system composed by two molecules bonded by a single hydrogen bond, but the system always drifted toward a bifurcated system. Consequently, single hydrogen bonds should not be discarded as possible contributors to this absorption.

Therefore, quantum mechanical calculations of chains of urea groups produce results that fit quite well with the experimental ones, helping to interpret them.

To finish with calculations, in Figure 11 the values for the enthalpy of formation are depicted. This parameter shows the decrease in energy when hydrogen bonds are formed. This quantity seems to tend to an asymptote when four or more urea groups are included on the chain.

Relationship between Hydrogen Bonding and Physical Properties. Before relating the hydrogen bonding results to the physical properties, the thermal stability of these copolymers was evaluated.

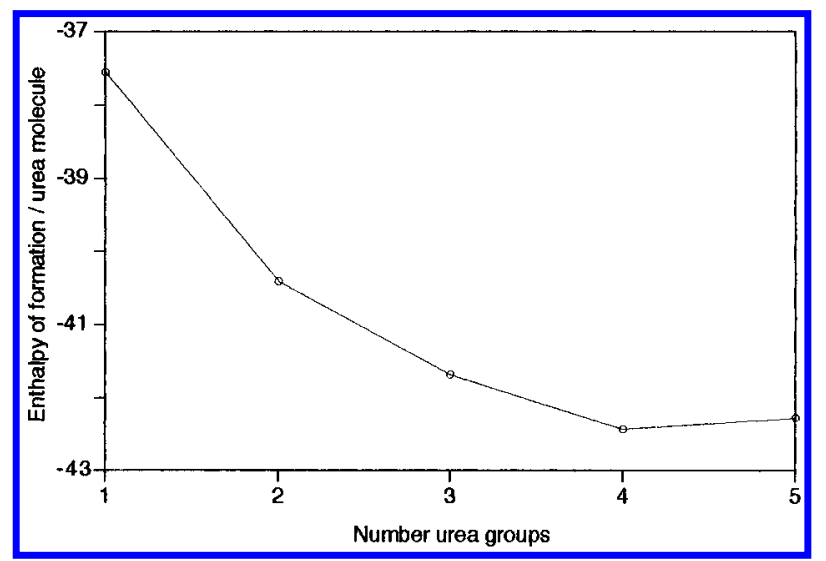

Figure 11. Variation of the calculated enthal py of formation per urea molecule with chain length.

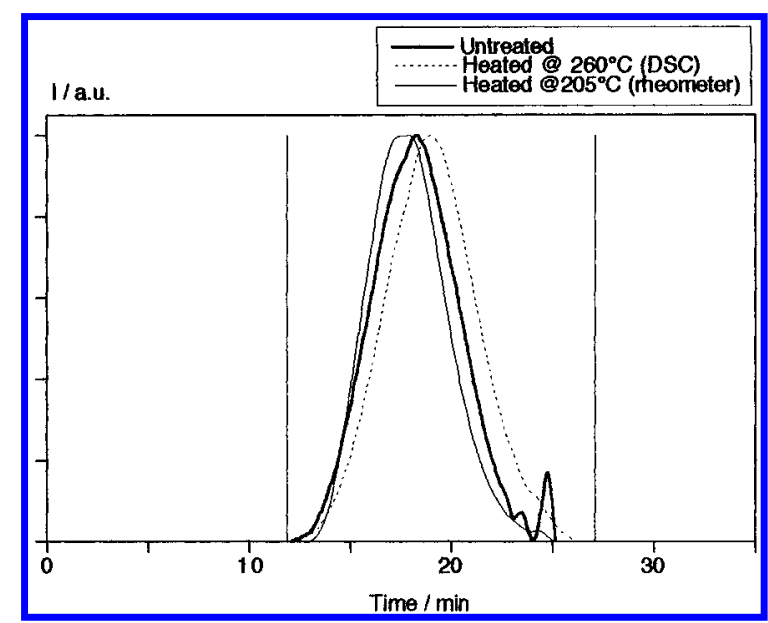

Figure 12. SEC chromatograms for the copolymer 970MDI after different treatments.

Thermogravimetric analysis ${ }^{30}$ demonstrated that degradation by weight loss occurs in two steps, with the first one associated with the urea groups. In the experimental conditions no appreciable weight loss is evident below $300{ }^{\circ} \mathrm{C}$. At $300{ }^{\circ} \mathrm{C}$, none of these copolymers has lost more than $0.25 \%$ of the initial weight.

To check the effect of other degradation mechanisms, the polymer molecular weight was measured by size exclusion chromatography (SEC). For the three copolymers, heating the sample to $260{ }^{\circ} \mathrm{C}$ in the DSC pan leads to a small decrease in the molecular weight. In Figure 12 the chromatograms for the copolymer 970MDI are displayed. Also included is the chromatogram of the copolymer after the treatment on the rheometer; at this temperature a slight increase in molecular mass is produced.

The rheological properties of 970MDI were measured, as can be seen in Figure 13 . Between 170 and $180^{\circ} \mathrm{C}$ a drop in the elastic modulus ( $\mathrm{G}^{\prime}$ ) takes place with the corresponding maximum in $\tan \partial$. On cooling the sample (heated to $205^{\circ} \mathrm{C}$ ), a recovery in modulus is produced in the range $182-192{ }^{\circ} \mathrm{C}$. The SAXS diffractogram of the sample heated on the rheometer is identical to the untreated polymer (Figure 3); therefore the system remains amorphous with a single phase, and no phase separation process is involved on the found transition. Thus, the transition has been shifted to higher temperatures after heating. At the same time, the elastic modul us has increased by more than 1 order of magnitude. This can be explained with the chains scheme. When the urea groups associate, they form 


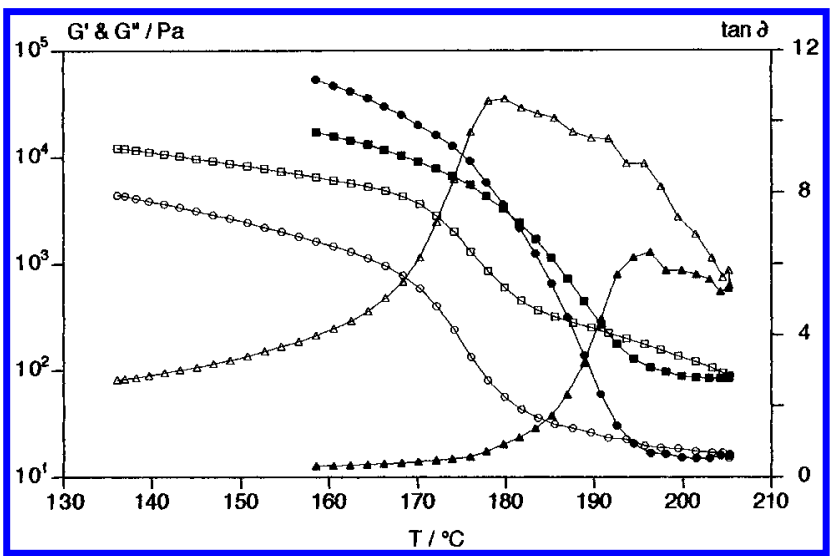

Figure 13. Variation of elastic modulus ( $\mathrm{G}^{\prime}$, circles), loss modulus (G", squares), and tan $\partial$ (triangles) on heating (open symbols) and on cooling (closed symbols) for copolymer 970MDI .

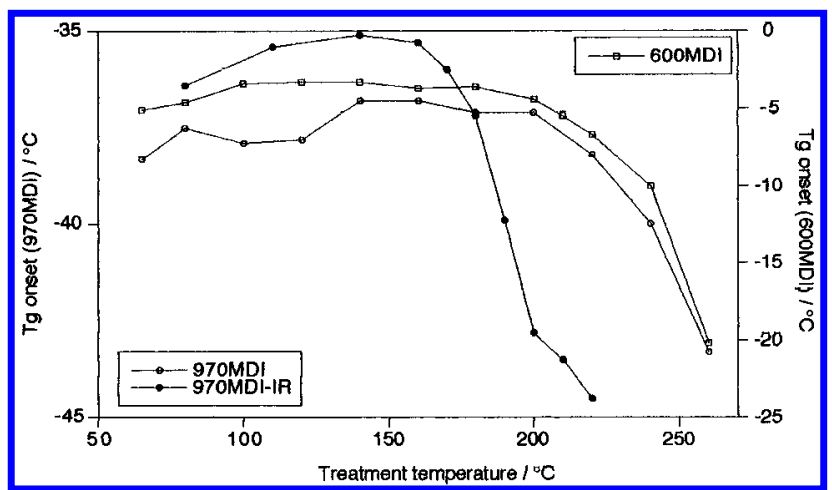

Figure 14. Changes in the glass transition onset of the polyether moiety for copolymers 970MDI and 600MDI after different "instantaneous" treatments and for copolymer 970MDI after holding at the treatment temperature for $15 \mathrm{~min}$ (970MDI-IR).

more (multifunctional) physical network nodes, increasing the value of $\mathrm{G}^{\prime}$; as in phase-segregated polyurethanes, ${ }^{31,32}$ poly(urethane-urea)s, ${ }^{33,34}$ and polyureas ${ }^{35-38}$ with the hard segment domains acting as multifunctional cross-link sites, the more phase segregation the higher the elastic modulus. The formation of biuret groups would produce an increase in molecular weight with the corresponding increase in modulus. However, the small amount of isocyanate groups created on heating does not disappear immediately on cooling, as it should if biuret groups were forming. Furthermore, the slight change in the molecular mass of the polymer after heating on the rheometer is not enough to justify such a change in modulus (Figure 12).

The changes on the polyether glass transition $\left(T_{g}\right)$ in $600 \mathrm{MDI}$ and $970 \mathrm{MDI}$ and the changes in the amount of crystallized ethylene oxide (\% EO) in 2260MDI were followed by calorimetry. Samples were heated to the desired temperature at $10^{\circ} \mathrm{C} / \mathrm{min}$ and then cooled at $-90{ }^{\circ} \mathrm{C}$ at the maximum rate of the instrument (320 ${ }^{\circ} \mathrm{C} / \mathrm{min}$ ). In the next scan, the value for $\mathrm{T}_{\mathrm{g}}$ (or \% EO) after this "instantaneous" heating to that temperature was measured and the sample was heated to the next temperature (usually 10 deg higher). In Figure 14 the changes in $\mathrm{T}_{\mathrm{g}}$ (almost identical graphs are obtained if $T_{g}$ is measured as the onset or the midpoint of the transition) can be observed. For copolymer 2260MDI only a small change is observed in \% EO (43-45\%). $\mathrm{T}_{\mathrm{g}}$ starts to decrease in both copolymers at about the same temperature, and it is explained by the association of urea groups. In these copolymers the soft segment mobility is restricted in the chain ends by the presence

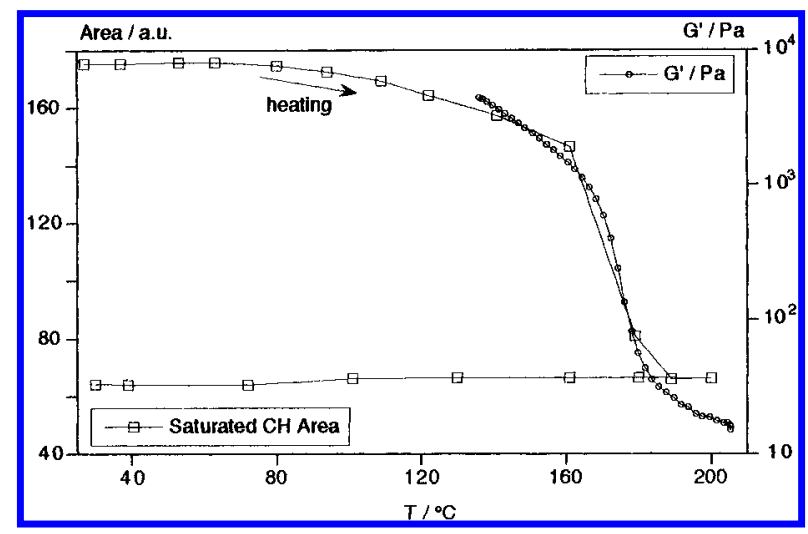

Figure 15. Comparison of the changes in the saturated $\mathrm{C}-\mathrm{H}$ area and in the elastic modulus with the temperature for copolymer 970MDI.

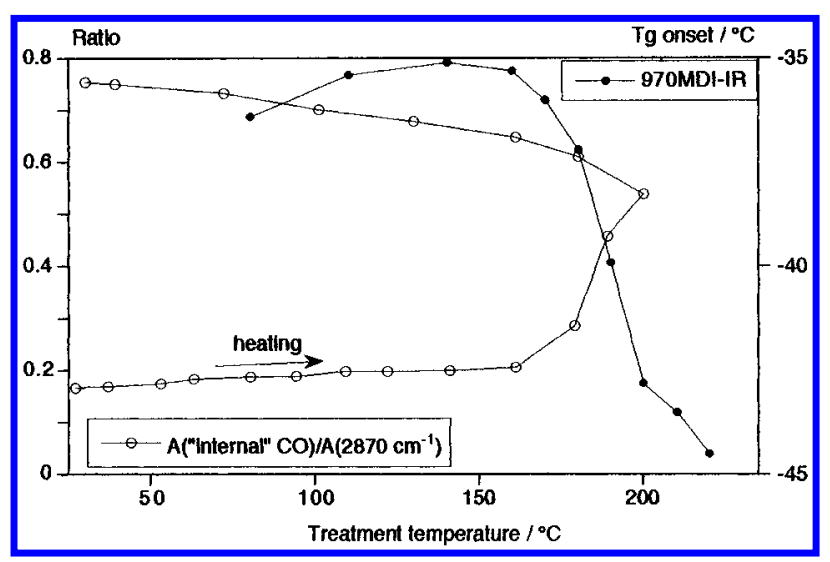

Figure 16. Comparison of the changes in the ratio $\mathrm{A}$ ("internal" $\mathrm{CO}) / \mathrm{A}\left(2870 \mathrm{~cm}^{-1}\right)$ and in the polyether glass transition onset with temperature for copolymer 970MDI.

of the rigid aromatic urea groups. These groups are able to interact either with other urea groups or with the ether groups of the soft segment chains, thus reducing their mobility (virtually producing a shortening of the length of the chains free to move). When urea groups associate in chains, fewer urea groups interact with ether groups, which causes an increase of the length between "cross-links" and, hence, a decrease of soft segment $\mathrm{T}_{\mathrm{g}}$. This change is well above the transition found with the rheometer and is partially due to the differences in the experiments. This can be clearly seen in the copolymer 970MDI. When the sample is maintained at the final temperature of the DSC run for 15 $\mathrm{min}$, as was done in the infrared experiments (970MDIIR in Figure 14), the decrease in the glass transition shifts to lower temperatures by approximately $40 \mathrm{deg}$.

In graphs 15 and 16 the results from the rheometer and the DSC are directly compared with the results obtained by infrared studies. The change in total area for saturated $\mathrm{C}-\mathrm{H}$ absorption that was related to a change in viscosity takes place at the same time as the drop in $G^{\prime}$ was found in the rheometer (Figure 15). The increase in "internal" $\mathrm{C}=\mathrm{O}$ absorption or in other words the increase in length of the urea chains is coincident with the decrease in soft segment $T_{g}$, demonstrating its direct relationship (Figure 16), and that it is posterior to the change in viscosity of the copolymer.

\section{Conclusions}

The IR bands for the $\mathrm{C}=\mathrm{O}$ region in the synthesized copoly(ether-urea)s were assigned under the assumption of the existence of chains of urea groups. The well- 
defined peak at high frequencies $\left(1694 \mathrm{~cm}^{-1}\right)$ was assigned to the "top" urea groups of the chains, and the well-defined peak at low frequencies $\left(1640 \mathrm{~cm}^{-1}\right)$, to the "internal" urea groups of the chains. The peak filling the gap between these two $\left(1666 \mathrm{~cm}^{-1}\right)$ was related with the help of quantum mechanical calculations to two contributions, while the shoulder at frequencies > 1694 $\mathrm{cm}^{-1}$ was associated with "isolated" urea groups and to diphenylurea groups arising from trans-urea reactions (the $\mathrm{N}-\mathrm{H}$ dipoles of the "bottom" and "isolated" urea groups hydrogen-bonded to ether groups).

The results from quantum mechanical calculations of these chains of hydrogen-bonded urea groups fit qualitatively well with the experimental infrared results supporting the above picture. Calculations fail to reproduce accurately the relative intensities of the peaks. They predict a higher intensity (absorption coefficient) for the "internal" urea groups, and besides, the larger the chains the higher the intensity, in opposition to experimental results where the $\mathrm{C}=\mathrm{O}$ absorption coefficient seems to be nearly independent of the state of hydrogen bonding.

Comparison of infrared, dynamic mechanical, and calorimetric data demonstrated that a transition is reached at high temperatures, being probably the glass transition of the bis(ureaphenyl)methane units, where the elastic modulus of the system drops. This transition is prior to the formation of large chains of urea groups, which in turn produces a decrease in the glass transition of the polyether moiety of the copolymer.

The interpretation of the peak at $1640 \mathrm{~cm}^{-1}$, that so far had been related to "ordered" urea segments inside the hard domains, should be revised, because this peak also appears in our copolymers, where no phase separation is observed. Therefore, this peak could have some contribution from chains of urea groups on the soft domains. However, in phase-separated systems, it is true that most of the urea groups would be on the hard domains and therefore most of the contribution to this peak would be related to these hard domains. F urthermore, under the proposed chains scheme, "ordered" urea groups would mean "internal" urea groups.

\section{Experimental Section}

Materials. The polyethers used were amine-functionalized poly(oxypropylene)-tipped poly(oxyethylene) of molecular masses approximately 600, 900, and 2000 (J effamine ED-600, ED-900 and ED-2001) supplied by Fluka. They were dried by the following method: a solution in benzene $30 \% \mathrm{w} / \mathrm{v}$ was prepared, $60-70 \%$ of the initial benzene was distilled off, and the remaining solution was frozen and dried in vacuum for $24 \mathrm{~h}$. The molecular mass was evaluated by titration of the amine ends with $0.1 \mathrm{~N} \mathrm{HCl}$ (mean of five determinations). The results obtained, 600, 970, and 2260, were used for the calculations in the synthesis. The 4,4'-diphenyl methane diisocyanate (MDI) supplied by Merck, which is a mixture of diand triisocyanates ca. 65:35, was purified by double distillation at reduced pressure $\left(\mathrm{bp}=190{ }^{\circ} \mathrm{C}\right.$ at $5 \mathrm{mmHg}$ ), collecting a transparent liquid that crystallized on cooling to give a white solid. The distilled product was stored at low temperature. Dichloromethane (Quimicen, Spain) was refluxed for $24 \mathrm{~h}$ over $\mathrm{KOH}$ and distilled immediately prior use.

To a solution of polyether in $15 \mathrm{~mL}$ of $\mathrm{CH}_{2} \mathrm{Cl}_{2}$ at $-5^{\circ} \mathrm{C}$, was added a stoichiometric amount of MDI (final solution $15 \% \mathrm{w} / \mathrm{v}$ ). After $30 \mathrm{~min}$ of stirring at $-5{ }^{\circ} \mathrm{C}$ and a further $5 \mathrm{~h}$ at room temperature, the solution was poured into $150 \mathrm{~mL}$ of diethyl ether and cooled overnight. The resulting precipitate was decanted and dried in high vacuum.

The name of the copolymers used in the text are 600MDI, $970 \mathrm{MDI}$, and 2260MDI in reference to the polyether molecular weight they are built from.
Methods of Characterization. Infrared spectra were recorded in transmission by a Perkin-EImer System 2000 FTIR spectrometer. Samples were pressed at $60^{\circ} \mathrm{C}$ between $\mathrm{CaF}_{2}$ plates until transmission of the sample in the $\mathrm{C}=\mathrm{O}$ region was more than $10 \%$. Temperature studies were conducted in a cell equipped with $4 \times 250 \mathrm{~W}$ high-density cartridge heaters (Godfrey Thermal Ltd., U.K.). The temperature in the cell was measured with J type thermocouples and controlled by a Macintosh II microcomputer equipped with Strawberry Tree Inc. Workbench v.3.1 system software and ACM2-12-8 (T51) data acquisition A-D hardware. ${ }^{39}$ Prior to the experiment, the temperature in the windows was calibrated with standards at a rate of $0.2{ }^{\circ} \mathrm{C} / \mathrm{min}$ to correct for the difference in temperature between the windows and the cell thermocouples readings. The temperature was constant within 0.5 deg. Spectra were recorded at several temperatures after holding the sample for 13-15 $\mathrm{min}$ at the given temperature. Sixteen scans at a resolution of $4 \mathrm{~cm}^{-1}$ were signal averaged at each temperature.

A Perkin-Elmer TGA-7 controlled by a microprocessor Perkin-EImer TAC 7/DX was used for thermogravimetric analysis. Samples with weight between 2 and $3 \mathrm{mg}$ were scanned with a heating rate of $10{ }^{\circ} \mathrm{C} / \mathrm{min}$ under a flux of nitrogen of $50 \mathrm{~mL} / \mathrm{min}$.

SEC was carried out using three polystyrene-divinylbenzene Polymer Laboratories columns of pore diameter size 500 , $10^{4}$, and $10^{5} \AA$. DMF $/ \mathrm{LiCl}(0.5 \% \mathrm{w} / \mathrm{v})$ was used as solvent, and the response was recorded with a UV detector $(271 \mathrm{~nm})$. Calibration was made with polystyrene standards.

SAXS measurements were made on Beamline 8.2 of the Synchrotron Radiation Source (SRS) at the SE RC Daresbury Laboratory, Warrington, U.K.

WAXD was carried out with a Philips Geiger instrument. A nickel filter gave predominantly $\mathrm{Cu} \mathrm{K} \alpha$ radiation of 1.542 $\AA$. Diffractograms were acquired at $2 \% \mathrm{~min}$.

Dynamic mechanical measurement was conducted in a Rheometrics Instrument in a plate-plate geometry $(25 \mathrm{~mm}$ diameter) at a frequency of $1 \mathrm{~Hz}, 5 \%$ strain, and a scanning rate of $2 \% \mathrm{~min}$. The cycle temperature was $135-205-155^{\circ} \mathrm{C}$. Analysis was done with Rheometrics Rhios v.4.2.2 software.

DSC scans were done in a Perkin-EImer DSC-4 connected to a data station model 3600. Samples weighting $10-20 \mathrm{mg}$ in open pans were run at $10^{\circ} \mathrm{C} / \mathrm{min}$ to measure the glass transition (and crystallization and melting in 2260MDI). Details of the programmed temperatures are in the text. Dry nitrogen was used as a purging gas.

Theoretical Calculations. Semiempirical calculations were performed using the original parameters of the program $A M 1^{40}$ and $P M 3^{41}$ semiempirical SCF-MO methods, based on the restricted Hartree-Fock (RHF) method, included in the program MOPAC version 6.0.42 These methods are commonly used in the theoretical studies of organic molecules that include hydrogen bonding. 26,43,44 These semiempirical methods are commonly accepted to allow a better description of the core-core repulsion in several compounds. ${ }^{45}$ The program ran on an ALPHA 2100 computer at the Computer Center of CSIC (Consejo Superior de Investigaciones Científicas, Madrid, Spain). Furthermore, some calculations were performed by using the Insight $1 \mathrm{I}^{46}$ and Cerius $2^{47}$ programs running on $a$ Silicon Graphics Indigo2 R-10000-Impact workstation.

Initial geometries were obtained by molecular mechanics $(\mathrm{MM}+)$ by means of the program Hyperchem version $4.5,{ }^{48}$ this program ran on a Silicon Graphics Indigo2 workstation. The results of this optimization were employed as input data for the semiempirical calculations. The same program and the program Cerius2 were used to visualize the structures obtained after MOPAC minimization. Geometries were optimized in internal coordinates. The optimization was stopped when Herbert or Peter tests were satisfied in the BroydenFletcher-Goldfarb-Shanno (BFGS) method. The PRECISE option was applied during the optimization process with the gradient norm set to 0.01 . The calculations were carried out with full geometry optimization (bond lengths, bond angles, and dihedral angles).

IR frequencies were calculated by using the FORCE keyword included in the MOPAC 6.0 program. ${ }^{27}$ 
Acknowledgment. We are indebted to the CICYT (MAT 95-0099 and MAT 95-0020) and one of us (A.M.F.) thanks the UE (ERB4001GT921602) for the financial support. We would like to thank Dr. Mike Elwell for the design of the temperature control system of the infrared cell, Dr. A. J . Ryan for the SAXS experiments, and $\mathrm{Dr}$. B. Komanschek for the realization of the rheometer test.

\section{References and Notes}

(1) Cooper, S. L.; Tobolsky, A. V. L. Appl. Polym. Sci. 1966, 10, 1837.

(2) Petrovic, Z. S.; Ferguson, J . Prog. Polym. Sci. 1991, 16, 695.

(3) Coleman, M. M.; Skrovanek, D. J .; Hu, J.; Painter, P. C. Macromolecules 1988, 21, 59.

(4) Seymour, R. W.; Estes, G. M.; Cooper, S. L. Macromolecules 1970, 3, 579 .

(5) Seymour, R. W.; Cooper, S. L. Macromolecules 1973, 6, 48.

(6) Paik Sung, C. S.; Schneider, N. S. Macromolecules 1975, 8, 68.

(7) Senich, G. A.; MacKnight, W. L. Macromolecules 1980, 13, 106.

(8) Rubner, M. F. Macromolecules 1986, 19, 2114.

(9) Nitzsche, S. A.; Hsu, S. L.; Hammond, P. T.; Rubner, M. F. Macromolecules 1992, 25, 2391.

(10) Ishihara, H.; Kimura, I.; Saito, K.; Ono, H. L. Macromol. Sci. Phys. 1974, B10, 591.

(11) Bonart, R.; Morbitzer, L.; Müller, E. H. L. Macromol. Sci. Phys. 1974, B9, 447.

(12) Paik Sung, C. S.; Smith, T. W.; Sung, N. H. Macromolecules 1980, 13, 117.

(13) Born, L.; Hespe, H. Colloid Polym. Sci. 1985, 263, 335.

(14) Priester, R. D., J r.; McClusky, J . V.; O'Neill, R. E.; Turner, R. B.; Harthcock, M. A.; Davis, B. L. Proceedings of the SPI33rd Annual PolyurethaneTechnical/ Marketing Conference, Orlando, FL; Technomic Publishing Co.: Lancaster, PA, 1990; p 527.

(15) Artavia, L. D.; Macosko, C. W. Proceedings of the SPI-33rd Annual Polyurethane Technical/ Marketing Conference, OrIando, FL; Technomic Publishing Co.: Lancaster, PA, 1990; p 554.

(16) Gower, L. A.; Lyman, D. J . L. Polym. Sci., Polym. Chem. 1995, 33, 2257.

(17) Luo, N.; Wang, D.-N.; Ying, S.-K. Polymer 1996, 37, 3577.

(18) Elwell, M. J .; Ryan, A. J .; Grünbauer, H.J . M.; Van Lieshout, H. C. Polvmer 1996, 37, 1353.

(19) Pollack, S. K.; Smyth, G.; Papadimitrakopoulos, F.; Stenhouse, P. J .; Hsu, S.L.; MacKnight, W. L. Macromolecules 1992, 25, 2381.

(20) Byrne, C. A.; Desper, C. R.; Schneider, N. S.; Li, Y.; Chu, B. Macromol. Symp. 1995, 91, 1.
(21) Zharkov, V. V.; Strikovsky, A. G.; Verteletskaya, T. E. Polymer 1993, 34, 938.

(22) Strikovsky, A. G.; Zharkov, V. V. Polymer 1993, 34, 3397.

(23) Strikovsky, A. G.; Zharkov, V. V.; Letunovsky, M. P. Macromol. Symp. 1995, 94, 181.

(24) Painter, P. C. Private communication.

(25) Scheirs, J .; Bigger, S. W.; Delatycki, O. Polymer 1991, 32, 2014.

(26) Stewart, J . J . P. Comput. Chem. 1988, 13, 157.

(27) Seeger, D. M.; Korzeniewski, C.; Kowalchyk, W. L. Phys. Chem. 1991, 95, 6871.

(28) Hocker, J . I. Appl. Polym. Sci. 1980, 25, 2879.

(29) Kotani, T.; Hayashi, S.; I shihara, H.; Matsui, T.J . Macromol. Sci., Phys. 1992, B31, 65.

(30) Marcos-Fernández, A. Ph.D. Thesis, Universidad Complutense de Madrid, Madrid, Spain, 1992.

(31) Bengtson, B.; Feger, C.; MacKnight, W. J .; Scheneider, N. S. Polymer 1985, 26, 895.

(32) Miller, J . A.; Lin, S. B.; Hwang, K. K. S.; Wu, K. S.; Gibson, P. E.; Cooper, S. L. Macromolecules 1985, 18, 32.

(33) Hartmann, B.; Duffy, J . V.; Lee, G. F.; Balizer, E. L. Appl. Polym. Sci. 1988, 35, 1829.

(34) Clift, S. M. L. Elast. Plast. 1991, 23, 67.

(35) Birch, A. J .; Stanford, J . L.; Ryan, A. L. Polym. Bull. 1989, $22,629$.

(36) Chen, Z. S.; Yang, W. P.; Macosko, C. W. Rubber Chem. Technol. 1988, 61, 86.

(37) Willkomm, W. R.; Chen, Z. S.; Macosko, C. W.; Gobran, D. A.; Thomas, E. L. Polym. Eng. Sci. 1988, 28, 888.

(38) Marcos, A.; Rodríguez, A.; González, L. J . Non-Cryst. Solids 1994, 172-174, 1125.

(39) Elwell, M. J .; Mortimer, S.; Ryan, A. L. Macromolecules 1994, $27,5428$.

(40) Dewar, M. J . S.; Zoebisch, E. G.; Healy, E. F.; Stewart, J . J . P. L. Am. Chem. Soc. 1985, 107, 3902.

(41) Stewart, J. J . P. L. Comput. Chem. 1989, 10, 209.

(42) Stewart, J.J. P. Semiempirical Molecular Orbital Methods. In Reviews in Computational Chemistry; Lipkowitz, K. B., Boyd, D. B., Eds.; VCH: New York, 1990.

(43) Dewar, M. J . S.; Storch, D. M. L. Am. Chem. Soc. 1985, 107, 3898.

(44) J urema, M. W.; Shield, G. C. L. Comput. Chem. 1993, 14, 89.

(45) MOPAC 6.0. QCPE 1990, 445

(46) Insight II, version 95.0. Molecular Modeling System, Biosym/ MSI: San Diego, CA, 1995.

(47) Cerius², version 2.0; Molecular Modeling System, Biosym/ MSI: San Diego, CA, 1996.

(48) Hyperchem 4.5; Molecular Modeling System, Hypercube Inc.: Waterloo, Ontario, Canada, 1995.

MA9619039 